\title{
Aurélie Adler, Éclats des vies muettes. Figures du minuscule et du marginal dans les récits de vie d'Annie Ernaux, Pierre Michon, Pierre Bergounioux et François Bon
}

\section{Stefano Genetti}

\section{(2) OpenEdition}

\section{Journals}

Edizione digitale

URL: http://journals.openedition.org/studifrancesi/2294

DOI: 10.4000/studifrancesi.2294

ISSN: 2421-5856

Editore

Rosenberg \& Sellier

\section{Edizione cartacea}

Data di pubblicazione: 1 aprile 2014

Paginazione: 189-190

ISSN: 0039-2944

\section{Notizia bibliografica digitale}

Stefano Genetti, «Aurélie Adler, Éclats des vies muettes. Figures du minuscule et du marginal dans les récits de vie d'Annie Ernaux, Pierre Michon, Pierre Bergounioux et François Bon », Studi Francesi [Online], 172 (LVIII | I) | 2014, online dal 01 avril 2014, consultato il 18 septembre 2020. URL : http:// journals.openedition.org/studifrancesi/2294; DOI : https://doi.org/10.4000/studifrancesi.2294

Questo documento è stato generato automaticamente il 18 settembre 2020 .

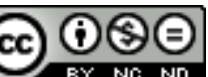

Studi Francesi è distribuita con Licenza Creative Commons Attribuzione - Non commerciale - Non opere derivate 4.0 Internazionale. 


\title{
Aurélie Adler, Éclats des vies muettes. Figures du minuscule et du marginal dans les récits de vie d'Annie Ernaux, Pierre Michon, Pierre Bergounioux et François Bon
}

\author{
Stefano Genetti
}

\section{NOTIZIA}

AURÉLIE ADLER, Éclats des vies muettes. Figures du minuscule et du marginal dans les récits de vie d'Annie Ernaux, Pierre Michon, Pierre Bergounioux et François Bon, Paris, Presses Sorbonne Nouvelle, 2012, pp. 330.

1 In questi récits de vie, «Les figures du minuscule et du marginal [...] mettent en lumière les entrecroisements ou les interactions entre les mutations de l'histoire et l'histoire du littéraire, entre les transformations sociales d'un pays et la redéfinition du rôle de l'écrivain dans la société française aujourd'hui» (p. 309). Così riassume l'A. nel concludere un'indagine che mobilita anche le acquisizioni della storiografia, dell'etnologia e della filosofia (Braudel, Certeau, Bourdieu, Augé, Rancière) al fine di sondare il sostrato epistemologico della «nouvelle inquiétude anthropologique» (p. 11) di cui è sintomatica la pratica di scrittura qui esaminata nelle sue valenze eticopolitiche, oltre che estetiche. Si tratta del racconto biografico nelle sue varie inflessioni contemporanee: vite minuscole e anteriori, racconti di filiazione e biofinzioni, vite frante e congetturali, doppiamente parziali: non solo perché lacunari ma anche perché raccontate da una prospettiva marcatamente soggettiva. Al confluire dei modelli rappresentati dalle Vies imaginaires di Schwob o dal biografema barthesiano ma anche dalla Vie des hommes infâmes di Foucault, questi racconti di vita - propria e altrui - 
coniugano riabilitazione del referente e demistificazione dell'illusione referenziale, circoscrivendo una modalità letteraria caratterizzata da interferenze enunciative $\mathrm{e}$ generiche e dalla ricercata sovrapposizione di fattuale e fittivo, di singolare e comunitario.

2 Le premesse teorico-critiche su cui poggia lo studio sono esposte nella lucida premessa. L'A. commenta tra l'altro i titoli (Miette di P. Bergounioux, Une femme di A. Ernaux, C'était toute une vie di F. Bon) di alcuni dei libri di cui analizza le figure - intese sia come personaggi che come micro-strutture testuali - evidenziando il doppio parametro, scalare e spaziale, che accomuna opere peraltro assai diverse fra loro: l'iscrizione della storia e del reale procede all'intersezione del minuscolo - che sostituisce l'eminente e l'esemplare ereditati dalla tradizione biografica, poiché si mira a restituire la vicenda di coloro che la memoria collettiva trascura - e del marginale, di ciò che si colloca en retrait rispetto alle norme dominanti e ai discorsi che le promulgano. Basato sulla «double opération de minusculisation des paramètres de la narration et/ou de marginalisation du romanesque» (p. 14), tale minimalismo narrativo concorre a rinnovare la percezione del fatto letterario nell'attuale panorama culturale.

Nella prima delle tre parti in cui il volume è suddiviso - «Des figures brisées par un changement d'ère culturelle» -, l'A. spazia tra gli autori del corpus mettendo in luce come questi frammenti di vite conferiscano non solo visibilità ma anche lustro quasi leggendario - di qui la scelta, nel titolo, dell'ambivalente sostantivo éclats - alle più banali figure del quotidiano. Saperi e mestieri, corpi e gesti, contrade e parlate di una Francia rurale e arcaica, in via di sparizione - quella di Bergounioux -, oppure anonime sagome urbane, sommerse nel grigiore dei sobborghi post-industriali, come nei journaux extimes di A. Ernaux, conoscono così una rigenerazione in quanto emblemi dell'origine perduta o dell'alienazione urbana.

Ripartita in sottocapitoli monografici, la seconda parte - «Des éclats de soi» - verte sulle ricadute espressive di tale rifondazione del racconto sulle rovine del romanesque. Germinazione parcellare dei biografemi, narrazione frammentaria e pluralità delle voci contribuiscono a ridefinire i mobili confini tra osservazione e introspezione, tra (auto)biografia e (auto)finzione. Inoltre, in filigrana, si profila un autoritratto dello scrittore che ricostruisce la propria genealogia umana e autoriale.

Sono queste strategie di autolegittimazione a essere interrogate nella terza parte «Résistances de littérature»-, dove l'analisi testuale si apre alla sociologia della letteratura intorno ai fenomeni di riconoscimento editoriale e di istituzionalizzazione illustrati dal caso di P. Michon, scrittore del minuscolo diventato incontournable. Da tutta una «littérature de la fin de la littérature» (p. 220) emerge in definitiva un engagement che concepisce la creazione in quanto condivisione, come avviene negli ateliers promossi da F. Bon e tesi a «ouvrir, par la mise en partage de la langue, des liens entre des communautés en éclats» (p. 315). 